\title{
Experimental investigation of angle length effect - angles in tension connected by one leg
}

\author{
W. Barcewicz, S. Wierzbicki \& M.A. Giżejowski \\ Warsaw University of Technology, Warsaw, Poland \\ S. Labocha \\ University of Technology in Katowice, Katowice, Poland \\ R. Czyż \\ ENPROM Ltd., Warsaw, Poland
}

\begin{abstract}
In the present paper, the results of experimental tests of angle specimens subjected to tension and connected by one leg are presented. Structural members of such a form are commonly applied to the steel lattice supports of overhead electrical lines. The bolted connections of angles connected by one leg to gusset plates are under tension and additional bending moment that results from the eccentricity of the bolt group. Majority of available existing experimental and numerical investigations regarding the bolted connections of steel angles in tension have been conducted using mostly short specimens. Within this paper, the influence of the specimen length on the behaviour of angles connected by one leg in tension is shown on the basis of the comparison of the results from the experimental tests of shorter and loger specimens of the same size of angle section.
\end{abstract}

\section{INTRODUCTION}

\subsection{General information}

Investigations presented in this paper are the part of the research works conducted by ENPROM Ltd. within the framework of the project No. POIR.01.01.01-00-0789/17 entitled „Elaboration of the new series of types of $400 \mathrm{kV}$ transmission towers and foundations suitable for them, including foundations to the use on grounds about particularly disadvantageous geotechnical parameters", co-financed by The National Centre for Research and Development in Poland.

Within the framework of the project, new types of transmission towers and innovative shallow foundations (prefabricated with special overlay plates, hybrid monolithic-prefabricated and special strengthened footings with anchoring micropiles) with the increased pull-off capacity have been elaborated. Besides of the unique full scale (1:1) experimental tests of the steel lattice transmission towers and different types of footing foundations, the essential part of the research work within the ENPROM project are complementary laboratory tests of tension connections of hot-rolled steel angles connected by one leg, typically used in the transmission towers of overhead high voltage electric lines.

The project was led in cooperation with the Faculty of Civil Engineering, Warsaw University of Technology. Research works in the field of steel structures are foreseen to the direct 
application at the construction of the latest overhead high voltage transmission lines in Poland and Europe.

\subsection{Aim and scope of the presented research}

The purpose of this paper is to present the experimental destructive tests of eighteen angle specimens connected by one leg to the gusset plates on both ends by means of bolted connections and subjected to tension, as well as to discuss the influence of the specimen length on their behaviour.

Motivation to study such an effect was the observations of the authors of this paper from the earlier tests of total ninety specimens consisted of different angle sections but of the same length, conducted in the laboratory of the Faculty of Civil Engineering, WUT within the ENPROM project introduced above. The bolted connections of angles connected by one leg, theoretically under axial tension, are in fact also subjected to bending moment that results from the eccentricities of the bolt group. It was observed that the smaller specimen length to its leg width ratio, the deformation of the angle specimen due to bending stresses was more and more visible. The majority of available existing experimental and numerical investigations regarding the bolted connections of steel angles in tension have been conducted using mostly short specimens, generally in the range of around 500 to $600 \mathrm{~mm}$ (e.g. Agrawal \& Gupta 2018, Bernatowska \& Ślęczka 2018, 2019, Geethu et al. 2014, Gupta \& Gupta 2004). Within this paper, the influence of the specimen length on the behaviour of angles connected by one leg in tension is shown on the basis of the comparison of the results from the experimental tests of shorter and longer specimens of the same size of angle section.

\section{EXPERIMENTAL TESTS}

\subsection{Description of the specimens and the test rig}

Specimens considered in the experimental tests described herein consist of angle section connected by one leg to the gusset plates on both ends. For the purpose of this publication two series of equal-leg angles are taken into account, namely L120 $\times 120 \times 8$ and L90 $\times 90 \times 6$. The experimental tests of the selected specimens were performed in two stages. Firstly, the set of short specimens of the length equal to $600 \mathrm{~mm}$ were tested. In the second stage, the tests of the longer specimens of $1500 \mathrm{~mm}$ long were performed. The summary of the specimens considered in the present paper is given in Table 1. Exemplary specimens from two length groups are presented in Figures 1 and 2.

All angle members are connected to steel gusset plates by means of lap bolted connections, using 3 bolts M20 cl. 8.8 at each end. The bolts were fastened with the controlled tightening

Table 1. Summary of the tested specimens.

\begin{tabular}{|c|c|c|c|c|}
\hline \multirow{2}{*}{$\frac{\text { Type of specimens }}{\text { Hot-rolled sections }}$} & \multicolumn{2}{|c|}{ Short specimens $(\mathrm{L}=600 \mathrm{~mm})$} & \multicolumn{2}{|c|}{ Long specimens $(\mathrm{L}=1500 \mathrm{~mm})$} \\
\hline & $\mathrm{L} 90 \times 90 \times 6$ & $\mathrm{~L} 120 \times 120 \times 8$ & $\mathrm{~L} 90 \times 90 \times 6$ & $\mathrm{~L} 120 \times 120 \times 8$ \\
\hline \multirow[t]{5}{*}{ Specimen names } & L90/6/3M20-1 & L120/8/3M20-1 & L90/6/3M20-6 & L120/8/3M20-6 \\
\hline & L90/6/3M20-2 & L120/8/3M20-2 & L90/6/3M20-7 & L120/8/3M20-7 \\
\hline & L90/6/3M20-3 & L120/8/3M20-3 & L90/6/3M20-8 & L120/8/3M $20-8$ \\
\hline & L90/6/3M20-4 & L120/8/3M20-4 & L90/6/3M20-9 & \\
\hline & $\mathrm{L} 90 / 6 / 3 \mathrm{M} 20-5$ & $\mathrm{~L} 120 / 8 / 3 \mathrm{M} 20-5$ & $\mathrm{~L} 90 / 6 / 3 \mathrm{M} 20-10$ & \\
\hline
\end{tabular}




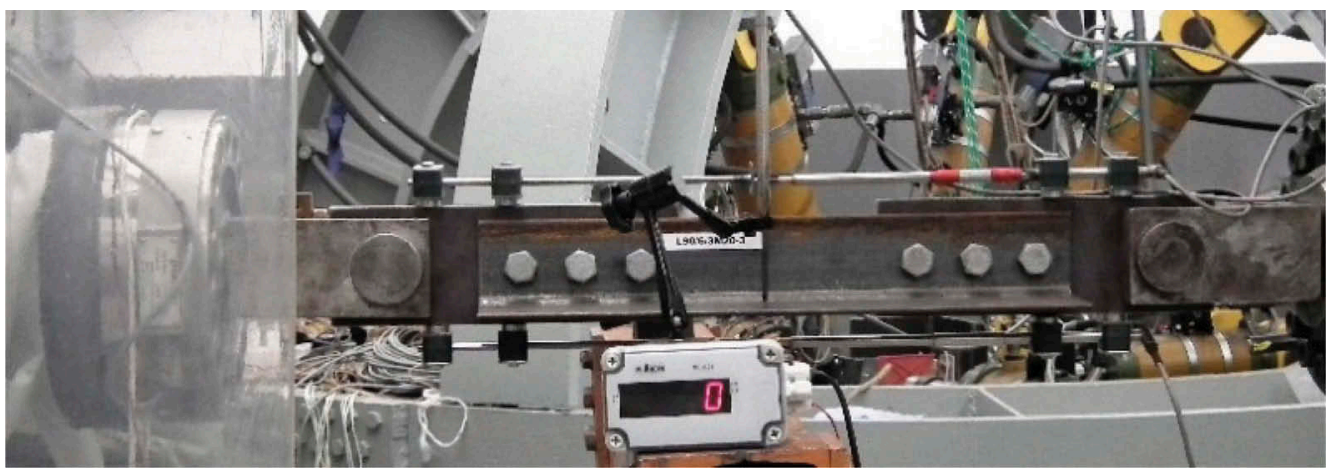

Figure 1. Exemplary short specimen.

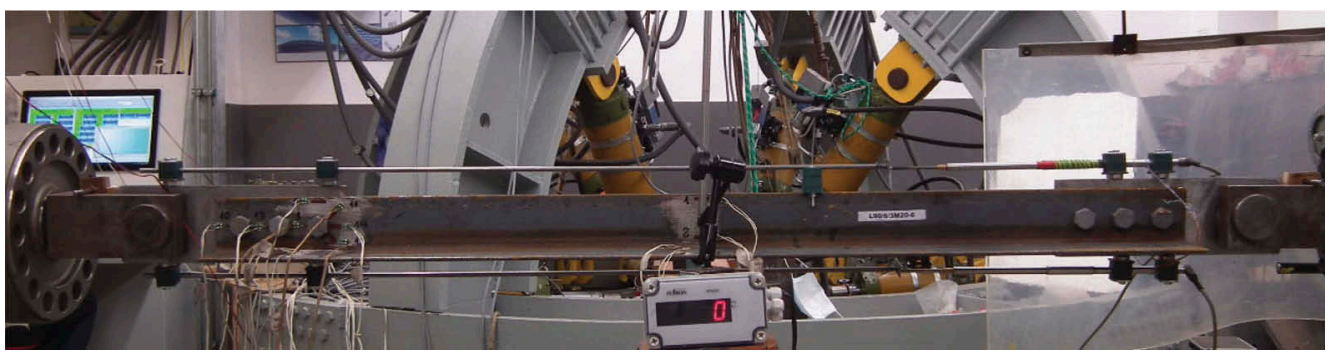

Figure 2. Exemplary long specimen.

moment equal to $246 \mathrm{Nm}$. End and edge distances $\left(e_{1}=40 \mathrm{~mm}, e_{2}=60 \mathrm{~mm}\right.$ for L120 $\times 120 \times 8$ and $45 \mathrm{~mm}$ for L $90 \times 90 \times 6)$, as well as the spacing between bolts $\left(p_{1}=65 \mathrm{~mm}\right.$ for L120 $\times 120 \times 8$ and $60 \mathrm{~mm}$ for L90×90×6), met the requirements of EN 1993-1-8 (CEN 2005). Dimensions of the gusset plates were properly fitted to the angle sections in order to avoid undesirable failure modes in the gusset plates and were equal to $28 \times 120 \times 360 \mathrm{~mm}$ and $15 \times 120 \times 350 \mathrm{~mm}$, respectively for L $120 \times 120 \times 8$ and L $90 \times 90 \times 6$. Both the hot-rolled sections as well as the gusset plates are made of steel grade $\mathrm{S} 355 \mathrm{~J} 2$.

The experimental tests were conducted using $1000 \mathrm{kN}$ universal testing machine, in which the specimens were placed horizontally. The gusset plates at both ends of the specimens were connected by pins to the grips of the testing machine.

\subsection{Description of the testing procedure}

The specimens were subjected to a monotonic tensile force, which was applied to horizontal steel grips that were fixed to the testing machine, as shown in Figures 1 and 2. The tests were carried out under displacement control at a possibly slowest steady speed up to a failure of the specimens.

Two linear variable displacement transducers (LVDTs) were attached to the gusset plates on the top and the bottom side of the plates. Their function was a measurement of specimen 
elongations. Moreover, two additional LVDTs were applied in order to measure out-ofplane displacement, one in the vertical direction and the other in the horizontal direction perpendicular to the longitudinal axis of a specimen. Selected specimens (two representatives from each series with $\mathrm{L} 90 \times 90 \times 6$ ) were also equipped in the set of strain gauges located close to one bolted connection at one end of the specimen and also in the middle of the specimen length.

Load and displacement data were collected by a data acquisition system and exported to Excel.

\subsection{Material properties of structural steel}

Additionally to the experimental tests of the specimens with bolted connections, tests of material properties were also conducted. From each angle type considered herein, three coupons were cut off and tested according to the requirements of EN ISO 6892-1 (CEN 2016).

Summary of the mechanical properties of the steel used for fabrication of the specimens is shown in Table 2, distinguishing sizes of an angle section as the original material for cutting the tensile coupons as well as the average values of the yield strength $f_{\mathrm{y}}$, the ultimate strength $f_{\mathrm{u}}$ and their standard deviations ( $s_{\mathrm{fy}}$ and $s_{\mathrm{fu}}$, respectively).

\subsection{Failure modes of the specimens}

The failure mode for the whole series of the short L $120 \times 120 \times 8$ angle specimens is presented in Figure 3a. It was the same for each specimen from this series and based on the angle net cross-section rupture with accompanying significant plastic deformations due to bending of the angle sections. The place of the net cross-section failure every time passes by the external bolt hole located closer to the midspan of the specimen. The series of short L90 $\times 90 \times 6$ angle specimen was destroyed in a similar manner as the described above (see Figure $3 \mathrm{~b}$ ), except specimen L90/6/3M20-4, in which the acting force immediately dropped down due to bending, before reaching damage of the net cross-section of the angle. The deformations due to bending were also observed but their range was smaller than in the group of short L120 $\times 120 \times 8$ angles.

In the case of both groups of the longer specimens, the deformations due to bending are not so visible, what is shown in Figure $3 \mathrm{c}$, d. The tests of the long L90 $\times 90 \times 6$ angle specimens were terminated due to net cross-section rupture (Figure 3d). While failure modes of the long L $120 \times 120 \times 8$ angles were more varied (Figure 3c). It can be distinguished three types: bolts shear with visible deformations of one angle end and ovalisation of bolt holes due to bearing of bolts (in L120/8/3M20-6), rupture of angle net cross-section (in L120/8/3M20-8) and simultaneous interaction of the bolts shear (two bolts were sheared) and tearing of the edge of angle section in the vicinity of the outer bolt (in L120/8/3M20-7).

Table 2. Summary of steel mechanical properties.

\begin{tabular}{|c|c|c|c|c|}
\hline $\begin{array}{l}\text { Angle section- length } \\
\text { (series type) }\end{array}$ & $\frac{f_{\mathrm{y}}}{\mathrm{MPa}}$ & $\frac{s_{\mathrm{fy}}}{\mathrm{MPa}}$ & $\frac{f_{\mathrm{u}}}{\mathrm{MPa}}$ & $\frac{s_{\mathrm{fu}}}{\mathrm{MPa}}$ \\
\hline $\begin{array}{l}\mathrm{L} 120 \times 120 \times 8-600 \mathrm{~mm} \\
\mathrm{~L} 120 \times 120 \times 8-1500 \mathrm{~mm}\end{array}$ & $\begin{array}{l}427 \\
427\end{array}$ & $\begin{array}{l}4.9 \\
4.1\end{array}$ & $\begin{array}{l}521 \\
524\end{array}$ & $\begin{array}{l}5.3 \\
4.8\end{array}$ \\
\hline $\begin{array}{l}\mathrm{L} 90 \times 90 \times 6-600 \mathrm{~mm} \\
\mathrm{~L} 90 \times 90 \times 6-1500 \mathrm{~mm}\end{array}$ & $\begin{array}{l}409 \\
428\end{array}$ & $\begin{array}{l}5.6 \\
1.8\end{array}$ & $\begin{array}{l}597 \\
579\end{array}$ & $\begin{array}{l}5.3 \\
8.9\end{array}$ \\
\hline
\end{tabular}


a)

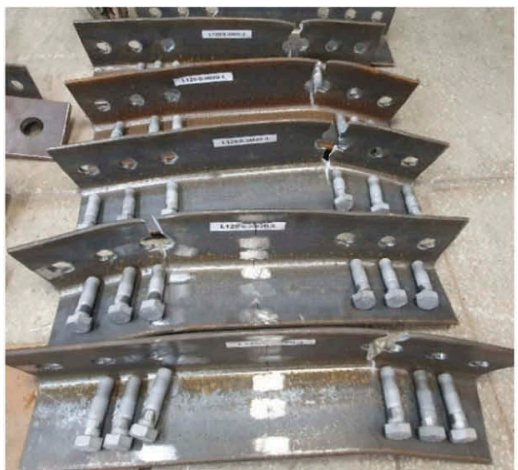

b)

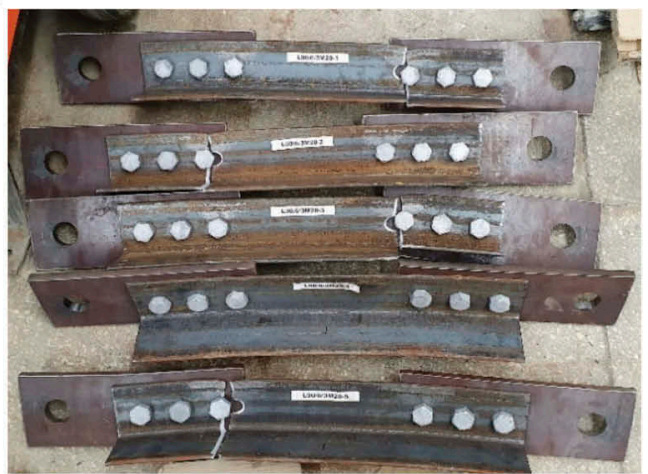

c)

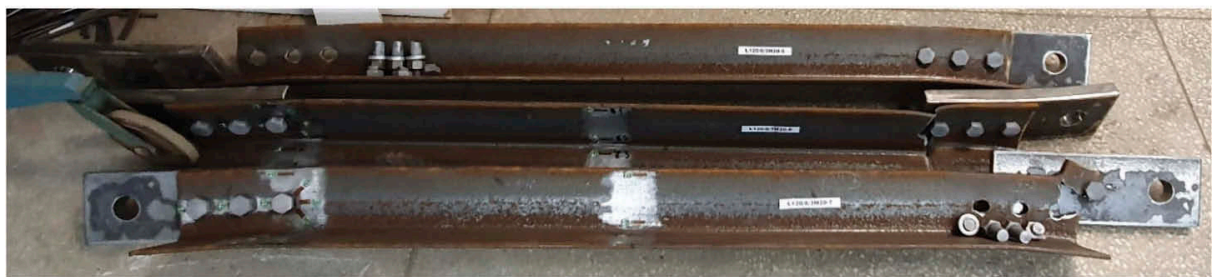

d)

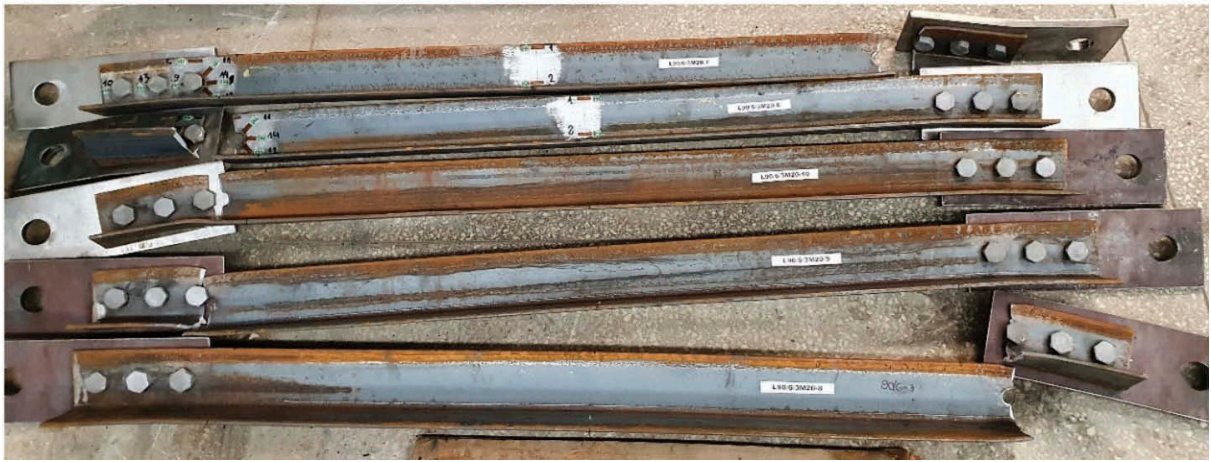

Figure 3. Overview of the specimen failure modes. a) Short L120 $\times 120 \times 8$ specimens after tests, b) Short

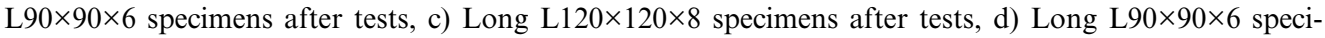
mens after tests.

\section{COMPARISON OF THE EXPERIMENTAL RESULTS}

The summary of the test results for all specimens considered herein is shown in Table 3 . The values of maximum forces are presented as well as accompanying deformations in the form of elongations of the angles, measured at the top and the bottom of the specimens and deflections in the midsection of the angles. In Table 3, their average values are also calculated. Moreover, graphical representation of the test results is shown, in the form of force-displacement curves for the selected specimens (continuous lines for short specimens, dashed lines for long specimens).

\section{CONCLUSIONS}

Within this paper, the influence of the specimen length on the behaviour of angles connected by one leg in tension is shown on the basis of the comparison of the results from the experimental tests of shorter and longer specimens of the sections L $120 \times 120 \times 8$ and L $90 \times 90 \times 6$. The 
Table 3. Summary of test results.

\begin{tabular}{|c|c|c|c|c|c|c|}
\hline \multirow[b]{3}{*}{ Series } & \multirow[b]{3}{*}{ Specimen } & \multirow[b]{2}{*}{$F_{\max }$} & \multicolumn{2}{|c|}{ Displacement at $F_{\max }$} & \multicolumn{2}{|c|}{ Deflection at $F_{\max }$} \\
\hline & & & $\begin{array}{l}\text { Top } \\
\text { LVDT }\end{array}$ & $\begin{array}{l}\text { Bottom } \\
\text { LVDT }\end{array}$ & $\begin{array}{l}\text { Horizontal } \\
\text { LVDT }\end{array}$ & $\begin{array}{l}\text { Vertical } \\
\text { LVDT }\end{array}$ \\
\hline & & $\mathrm{kN}$ & $\mathrm{mm}$ & $\mathrm{mm}$ & $\mathrm{mm}$ & $\mathrm{mm}$ \\
\hline \multirow{6}{*}{ L120×120×8 } & L120/8/3M20-1 & 540.62 & 38.85 & 27.88 & 14.36 & 9.66 \\
\hline & L120/8/3M20-2 & 529.91 & 41.35 & 31.56 & 18.88 & 12.90 \\
\hline & L120/8/3M20-3 & 541.50 & 42.77 & 31.93 & 15.19 & 10.54 \\
\hline & L120/8/3M20-4 & 533.73 & 35.56 & 26.37 & 12.95 & 17.35 \\
\hline & L120/8/3M20-5 & 549.36 & 45.28 & 40.61 & 13.11 & 15.69 \\
\hline & Average values & 539.02 & 40.76 & 31.67 & 14.90 & 13.23 \\
\hline \multirow{4}{*}{$\begin{array}{l}\text { Long } \\
\text { L120 } \times 120 \times 8\end{array}$} & L120/8/3M20-6 & 574.80 & 44.39 & 32.51 & 20.79 & 18.12 \\
\hline & L120/8/3M20-7 & 566.20 & 55.37 & 30.48 & 19.20 & 19.25 \\
\hline & L120/8/3M20-8 & 567.65 & 42.30 & 27.66 & 19.94 & 19.75 \\
\hline & Average values & 569.55 & 47.35 & 30.22 & 19.98 & 19.04 \\
\hline \multirow{6}{*}{ Short L90×90×6 } & L90/6/3M20-1 & 328.52 & 23.92 & 12.67 & 12.27 & 10.32 \\
\hline & L90/6/3M20-2 & 346.78 & 23.07 & 12.74 & 9.99 & 14.19 \\
\hline & L90/6/3M20-3 & 325.48 & 22.98 & 14.65 & 11.91 & 6.24 \\
\hline & L90/6/3M20-4 & 362.12 & 23.35 & 11.29 & 11.88 & 13.59 \\
\hline & L90/6/3M20-5 & 364.64 & 26.14 & 12.10 & 10.93 & 17.30 \\
\hline & Average values & 345.50 & 23.89 & 12.69 & 11.40 & 12.33 \\
\hline \multirow[t]{6}{*}{ Long L90×90×6 } & L90/6/3M20-6 & 351.05 & 28.62 & 19.68 & 17.72 & 12.50 \\
\hline & L90/6/3M20-7 & 357.29 & 33.87 & 20.26 & 18.90 & 15.04 \\
\hline & L90/6/3M20-8 & 350.50 & 28.99 & 16.75 & 19.53 & 13.12 \\
\hline & L90/6/3M20-9 & 354.82 & 65.77 & 34.23 & 18.65 & 10.52 \\
\hline & L90/6/3M20-10 & 350.40 & 30.34 & 29.70 & 17.30 & 11.27 \\
\hline & Average values & 352.81 & 37.52 & 24.12 & 18.42 & 12.49 \\
\hline
\end{tabular}

a)

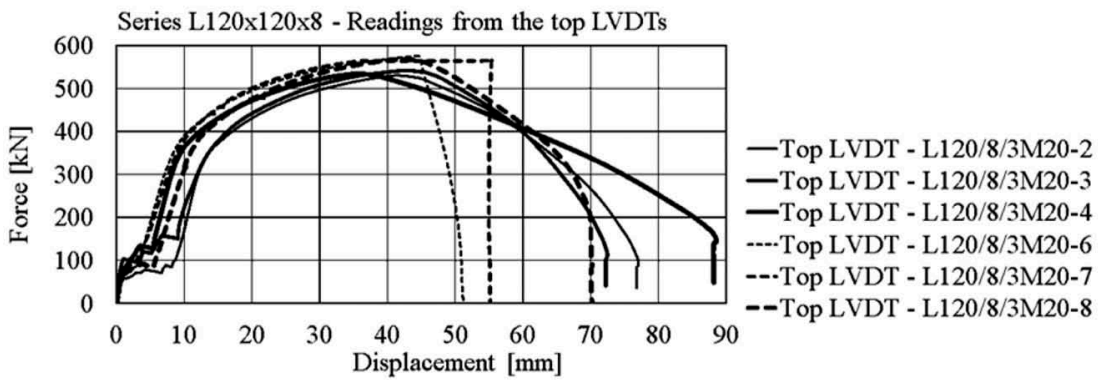

b)

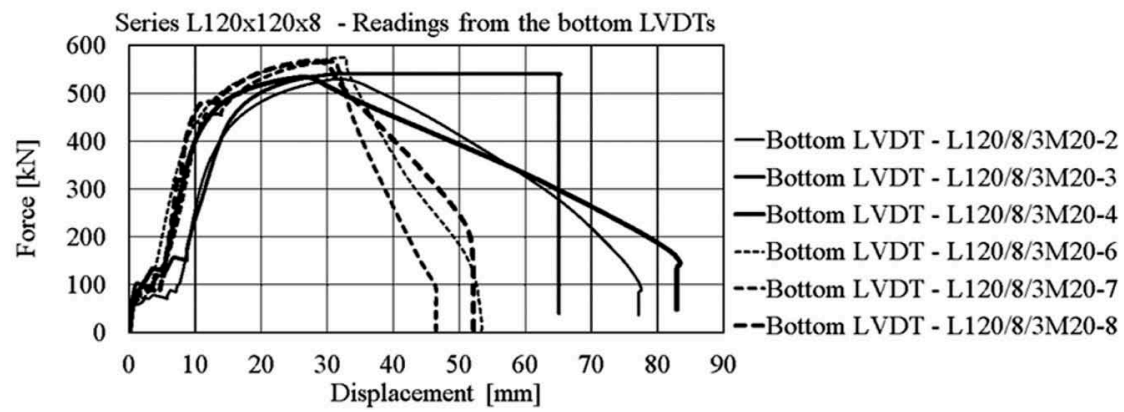

Figure 4. Load - displacement relationships for the selected specimens made of section L120×120×8 
a)

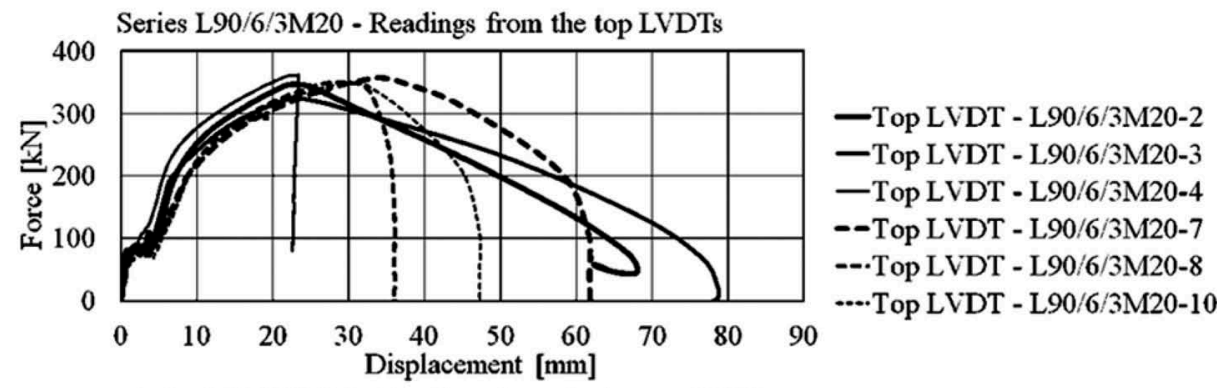

b)

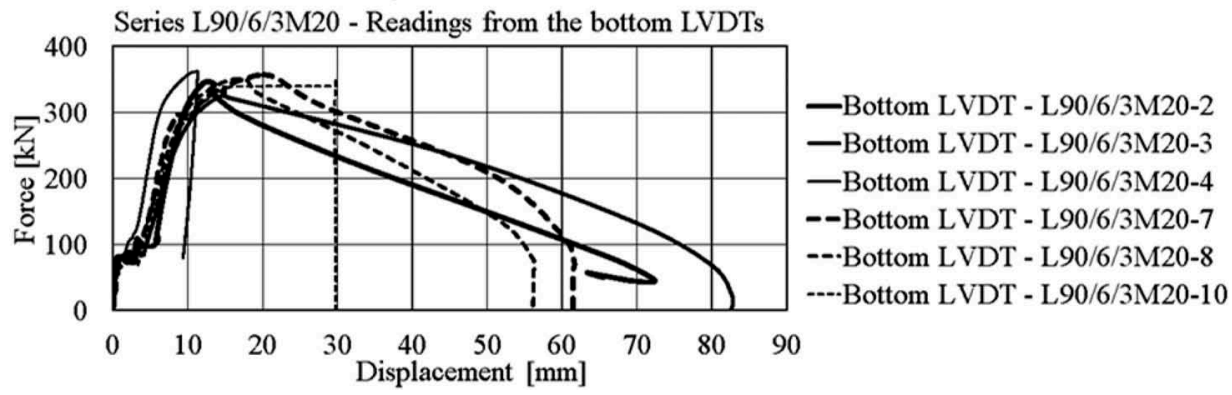

Figure 5. Load - displacement relationships for the selected specimens made of section L $90 \times 90 \times 6$.

higher influence of the specimen length is more visible in the series made of L120 $120 \times 8$. On this stage of research, it was clearly visible that the longer specimens reached a higher ultimate force of more than $5 \%$ in comparison to the shorter counterparts. The ultimate forces of shorter angle specimens, commonly tested by researchers, might be slightly underestimated due to a length effect with extra bending along the specimen length, not present in the real behaviour of slender tensile members.

\section{REFERENCES}

Agrawal, D. \& Gupta, M.K. 2018. Analysis of hot-rolled steel angles under tension. International Research Journal of Engineering and Technology 5(08): 1071-1074.

Bernatowska, E. \& Ślęczka, L. 2018. Stress and Strain concentrations in steel angle tension members connected by one leg. Journal of Civil Engineering, Environment and Architecture 65(2/18): 5-16.

Bernatowska, E. \& Ślęczka, L. 2019. Net section fracture assessment of steel bolted joints with shear lab effect. MATEC Web of Conferences 262, 09002 (2019): 1-8.

CEN. 2005. EN 1993- 1-8.Eurocode 3: Design of steel structures - Part 1-8: Design of joints. Brussels: CEN.

CEN. 2016. EN ISO 6892-1:2016. Metallic materials: Tensile testing - Part 1: Method of test at room temperature. (ISO 6892-1:2016). Brussels: CEN.

Geethu C.V., Unni Kartha G. \& Usha S. 2014. Effect of connection eccentricity in the behaviour of steel tension members. International Journal of Civil Engineering and Technology 5(12): 56-65.

Gupta M. \& Gupta L.M. 2004. Evaluation of stress distribution in bolted steel angles under tension. Electronic Journal of Structural Engineering 4: 17-27. 